\title{
Low Rate of Membrane Lithium Transport during Treatment Correlates with Outcome of Maintenance Pharmacotherapy in Bipolar Disorder
}

\author{
Alan G. Mallinger, M.D., Ellen Frank, Ph.D., Michael E. Thase, M.D., Christine S. Dippold, B.S.,
} and David J. Kupfer, M.D.

Lithium is transported across cell membranes by an exchange diffusion process $\left(\mathrm{Na}^{+}-\mathrm{Li}^{+}\right.$countertransport) that is inhibited during lithium treatment. We hypothesized that low rates of lithium efflux (a potential manifestation of strong transport inhibition) would be associated with better clinical outcome of maintenance pharmacotherapy. We measured the erythrocyte (RBC) apparent rate constant for lithium efflux $\left(k_{\text {exch }}\right)$ in 22 patients with bipolar disorder who had been euthymic on lithium for 1 month.

Subsequently, clinical mood ratings and in vivo RBC: plasma lithium ratios (LiR) were determined monthly. Outcome was categorized according to whether subjects completed 1 year of successful maintenance treatment $(\mathbf{n}=$ 10), experienced a recurrent affective episode $(\mathrm{n}=8)$, or dropped out $(\mathrm{n}=4)$. The $k_{\text {exch }}$ at the outset of the study was significantly lower (potentially because of greater transport inhibition) in 1-year completers than in patients with recurrences or those who dropped out (median $k_{\text {exch }}=0.09$, 0.24 , and $0.27 h^{-1}$, respectively; $\left.\mathrm{p}<.03\right)$. Moreover, $77 \%$ of patients with a $k_{\text {exch }}$ of $0.11 \mathrm{~h}^{-1}$ or lower were successfully maintained on lithium for 1 year, whereas only $23 \%$ of those with a $k_{\text {exch }}$ greater than or equal to $0.12 \mathrm{~h}^{-1}$ had a successful treatment outcome. LiR measured during the course of maintenance treatment was significantly higher (suggesting greater transport inhibition) in 1-year completers than in noncompleters (recurrences and dropouts). Measurement of $k_{\text {exch }}$ at an early point in treatment may provide a means for prospectively identifying those bipolar patients at greater risk for failure of maintenance lithium therapy. [Neuropsychopharmacology 16:325-332, 1977] (c) 1997 American College of Neuropsychopharmacology
KEY WORDS: Bipolar disorder; Lithium; Drug therapy; Cell membrane; Ion transport

After more than four decades of clinical use, lithium remains a cornerstone in the treatment of bipolar disorder, and the standard against which new treatments are

From the Departments of Psychiatry (AGM, EF, MET, DJK), Pharmacology (AGM), Psychology (EF), and Neuroscience (DJK), University of Pittsburgh School of Medicine, Pittsburgh, PA; the Western Psychiatric Institute and Clinic (CSD), Pittsburgh, PA.

Address correspondence to: Alan G. Mallinger, M.D., Western Psychiatric Institute and Clinic, $3811 \mathrm{O}^{\prime}$ Hara Street, Pittsburgh, PA 15213.

Received February 7, 1996; accepted October 10, 1996. evaluated (Price and Heninger 1994). Nevertheless, a substantial proportion of bipolar patients fail to respond adequately to maintenance treatment with this agent (Prien and Gelenberg 1989; Harrow et al. 1990). The studies described here were undertaken in an effort to delineate biological correlates of responsiveness to lithium maintenance treatment.

Lithium is transported across cell membranes by an exchange diffusion process referred to as $\mathrm{Na}^{+}-\mathrm{Li}^{+}$ countertransport (Haas et al. 1975; Duhm et al. 1976; Pandey et al. 1978). This transport mechanism appears to be active in the membranes of cells from many types of tissues and to play a significant role in the biological 
disposition of clinically administered lithium (Ehrlich et al. 1984; Mallinger et al. 1985; Weder 1986; Rybakowski et al. 1988).

Transmembrane ion movement via $\mathrm{Na}^{+}-\mathrm{Li}^{+}$countertransport is typically impeded during lithium treatment because of reduced affinity of the intracellular transport sites for lithium (Ehrlich et al. 1981; Diamond et al. 1983; Amsterdam et al. 1988; Mallinger et al. 1990). As a result, the shape of the Michaelis-Menten curve is altered in such a way that, for intracellular lithium concentrations on the linear portion of the curve below saturation, the apparent rate constant for lithium efflux $\left(k_{\text {exch }}\right)$ is reduced. The magnitude of this effect is influenced by the dose and duration of lithium administration (Meltzer et al. 1977; Ehrlich et al. 1981).

In a previous investigation, we found that the degree of transport inhibition due to lithium treatment varied considerably among individuals (Mallinger et al. 1990). Therefore, for the studies described here, we used erythrocyte $(\mathrm{RBC})$ membrane lithium transport during lithium treatment as a physiological marker of lithium action. Our hypothesis is that reduced $\mathrm{k}_{\text {exch }}$ (potentially because of stronger lithium action) measured prospectively at the initiation of maintenance treatment would be associated with better outcome when patients with bipolar disorder were treated with lithium for maintenance pharmacotherapy. We also measured the in vivo ratio of RBC:plasma lithium in blood samples collected at monthly intervals during the maintenance treatment trial. This parameter indirectly reflects lithium transport activity and generally increases when lithium efflux via $\mathrm{Na}^{+}-\mathrm{Li}^{+}$countertransport is inhibited (Rybakowski et al. 1978).

\section{METHODS}

\section{Subjects}

The bipolar patients who participated in this investigation $(n=22)$ were subjects in the Maintenance Therapies in Bipolar Disorder study (MH29618) performed at Western Psychiatric Institute and Clinic. The Schedule for Affective Disorders and Schizophrenia (Endicott and Spitzer 1978) was administered to each subject at a structured interview, and diagnoses were established according to the Research Diagnostic Criteria (RDC) (Spitzer et al. 1978). All patients both met criteria for a lifetime diagnosis of bipolar 1 disorder and had an index episode of mania or major depression. Subjects were free of major medical disorders, as determined by physical examinations and routine clinical laboratory tests.

\section{Treatment}

Lithium carbonate was used as the primary pharmacotherapeutic intervention for the index episode, supple- mented when necessary with neuroleptic (typically perphenazine) for psychotic symptoms, lorazepam for nonpsychotic manic agitation, or antidepressant (typically tranylcypromine, imipramine, or paroxetine). $\mathrm{Pa}$ tients also were randomly assigned to a nonpharmacological treatment consisting of weekly visits for either standard medication clinic management or an experimental form of psychotherapy (Interpersonal and Social Rhythm Therapy, IPSRT, Frank et al. 1994).

After successful treatment of the index affective episode (preliminary phase treatment) as outlined, euthymic patients were maintained on a stable dose of lithium for one month. No medications other than lithium were administered during this month, except for one patient who was treated with adjunctive thioridazine, and two other patients who received adjunctive tranylcypromine. These adjunctive medications were used only in cases where lithium monotherapy was therapeutically insufficient to achieve a euthymic state. At the end of this 1-month euthymic interval, RBCs were obtained to measure $\mathrm{k}_{\mathrm{exch}}$. At the same time, subjects were rerandomized with respect to their nonpharmacological treatment assignment, and the preventative phase of the study began. During this phase, patients were kept on a constant dose of lithium as maintenance treatment and were seen for six initial biweekly visits and subsequently at monthly intervals. The three patients who received adjunctive medications, as noted, were kept on constant doses of these agents. Data from the first year of maintenance treatment are included in this report.

\section{Laboratory Procedures}

The $\mathrm{k}_{\text {exch }}$ measurements were performed according to a modification of a general method described previously (Mallinger et al. 1990). RBCs were collected from venous blood and then preincubated in vitro so that they would contain between 0.48 and 0.76 mmoles lithium/L $\mathrm{RBCs}$ (mean $\pm \mathrm{SD}=0.55 \pm 0.07$ ). This preincubation was conducted for 65 minutes in media containing 0 to $7.6 \mathrm{mM} \mathrm{LiCl}$ (depending on the amount of lithium initially present in the cells) as determined from the formula: Media $\mathrm{LiCl}(\mathrm{mM})=(0.5-\mathrm{RBC} \mathrm{Li}) / 0.05$, where $\mathrm{RBC} \mathrm{Li}$ represents the lithium already present in cells (in mmoles/L RBCs) prior to the preincubation. In cases where this formula produced a negative number for media $\mathrm{LiCl}$ (i.e., when initial $\mathrm{RBC} \mathrm{Li}>0.5$ ), no $\mathrm{LiCl}$ was included in the media. The preincubation media also contained 127.4 to $135 \mathrm{mM} \mathrm{KCl}$ (adjusted based on the $\mathrm{LiCl}$ concentration used, to provide constant osmolarity) and $20 \mathrm{mM}$ Tris buffer.

At the end of the preincubation, the cells were washed three times with ice-cold isoosmotic $\mathrm{MgCl}_{2}$ to remove extracellular lithium and divided into two frac- 
tions, one of which was incubated for 90 minutes in isoosmotic buffer medium containing $130 \mathrm{mM} \mathrm{NaCl}$, while the other was simultaneously incubated in a medium that was sodium-free. The media also contained 4 or $134 \mathrm{mM} \mathrm{KCl}$ (to provide constant osmolarity), $1 \mathrm{mM}$ $\mathrm{MgCl}_{2}, 1.2 \mathrm{mM} \mathrm{CaCl}, 10 \mathrm{mM}$ dextrose, $10 \mathrm{mM}$ Tris buffer, and $0.2 \mathrm{mM}$ ouabain. The cell suspensions were sampled at $0,30,60$, and 90 minutes after the start of the incubation.

RBCs were separated from the sample aliquots by centrifugation, washed once in ice-cold isoosmotic $\mathrm{MgCl}_{2}$, and hemolyzed by diluting 1:8 with deionized, distilled water. The lithium content of the hemolyzates was determined (after a second 1:10 dilution) using atomic absorption spectroscopy (Perkin-Elmer model 305-B, equipped with a Hewlett-Packard 34701A/34740A 4.5digit voltmeter/display as a readout device). Hemoglobin content of the hemolyzates was measured spectrophotometrically at a wavelength of $540 \mathrm{~nm}$, after addition to cyanmethemoglobin reagent containing $0.1 \%$ Triton $X-100$. The hemoglobin and hematocrit values measured in whole blood were then used to calculate cell lithium content (in mmoles/L RBCs).

In the presence of extracellular sodium, lithium efflux occurs via both $\mathrm{Na}^{+}-\mathrm{Li}^{+}$countertransport and passive diffusion, whereas in the absence of sodium, only passive diffusion is operative. Thus, the difference between transport rates into these two types of media provides a measure of sodium-coupled lithium efflux via the $\mathrm{Na}^{+}-\mathrm{Li}^{+}$countertransport system.

The apparent rate constants for lithium transport into sodium-containing and sodium-free media $\left(\mathrm{k}_{\text {total }}\right.$ and $\mathrm{k}_{\text {passive, }}$ respectively) were calculated according to the following formula:

\section{$k_{x}=$ Lithium Efflux/Mean Lithium Content}

where lithium efflux is the rate of change in cellular lithium concentration (determined from the slope of a line fitted by the method of least-squares to the RBC lithium vs. time data, see Figure 1) and mean lithium content is the average of cellular lithium concentration measurements performed at the beginning and at the end of the incubations. The value of $k_{\text {exch }}$ was then calculated from the difference between $\mathrm{k}_{\text {total }}$ and $\mathrm{k}_{\text {passive }}$.

Following the initial determinations of $k_{\text {exch }}$ at the beginning of maintenance treatment (after 1 month of stable mood ratings following resolution of the index episode) additional blood samples were collected from patients monthly during maintenance treatment to determine in vivo RBC:plasma lithium ratios ( $\mathrm{LiR})$. RBCs were separated from plasma by centrifugation, lithium concentrations of RBCs and plasma were measured by atomic absorption spectroscopy, and the LiR values were calculated by dividing RBC by plasma lithium concentrations.

\section{Statistical Analyses}

Statistical analysis was performed with either SPSS for Windows 6.1 (SPSS, Inc., Chicago, IL), Prophet 4.0 (BBN Systems and Technologies, Cambridge, MA), or SAS 6.10 (SAS Institute, Inc., Cary, NC). For tests on the main hypothesis, which predicted the direction of expected differences, one-tailed tests were used. Otherwise, two-tailed tests were performed. Coefficient of variation $(\mathrm{CV})$ was calculated from the formula $\mathrm{CV}=$ ([standard deviation/mean] $\times 100$ ).

\section{RESULTS}

\section{Subject Characteristics}

Subjects were categorized, based on outcome during the first year of maintenance treatment, as 1-year completers $(n=10)$, recurrences despite maintenance therapy $(n=8)$, or dropouts $(n=4)$. Table 1 presents data on the demographic and baseline clinical characteristics of the subject groups. The groups did not differ significantly in the proportion of males/females, age at entry to the study, index episode type, duration of the index manic or depressive episode, baseline symptom severity, age at first manic episode, number of previous manic episodes, age at first depressive episode, number of previous depressive episodes, or psychosocial treatment

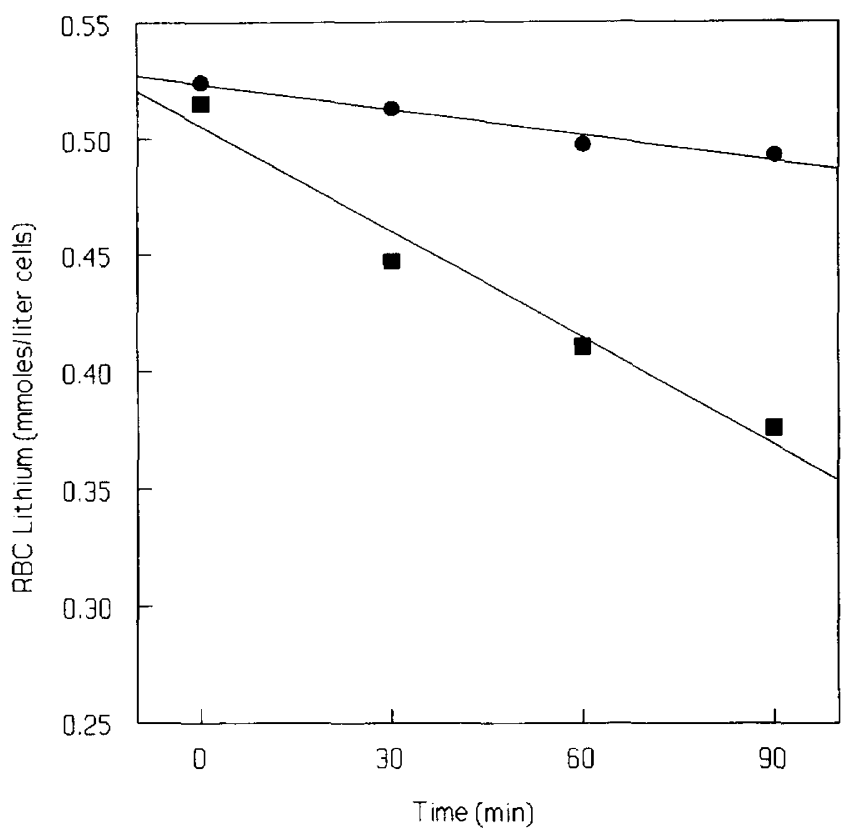

Figure 1. Plot of RBC lithium concentration versus time for a representative subject (ID 27207) during the 90-minute incubation procedure used to determine $\mathrm{k}_{\text {exch }}$. Circles, data from cells incubated in sodium-free media. Squares, data from cells incubated in sodium-containing media. Lines were fitted to the two types of data by the method of least squares. 
Table 1. Subject Characteristics by Outcome Group

\begin{tabular}{|c|c|c|c|}
\hline Subject Characteristics & $\begin{array}{l}\text { Dropouts } \\
(n=4)\end{array}$ & $\begin{array}{c}\text { Recurrences } \\
(n=8)\end{array}$ & $\begin{array}{l}\text { One-Year } \\
\text { Completers } \\
(n=10)\end{array}$ \\
\hline $\operatorname{Sex}(M / F)^{a}$ & $2 / 2$ & $3 / 5$ & $5 / 5$ \\
\hline Age $(\mathrm{yrs})^{b}$ & $37.3 \pm 5.9(39)$ & $36.8 \pm 11.3(40.5)$ & $41.7 \pm 11.5(37.5)$ \\
\hline Index episode type $(\mathrm{M} / \mathrm{D} / \mathrm{X} / \mathrm{C})^{a_{,} c}$ & $2 / 2 / 0 / 0$ & $4 / 3 / 0 / 1$ & $4 / 4 / 1 / 1$ \\
\hline Index mania duration (wks) ${ }^{d}$ & $12.7 \pm 10.0(9)$ & $9.7 \pm 10.6(5.5)$ & $8.5 \pm 8.7(4.5)$ \\
\hline Index depression duration (wks) ${ }^{b}$ & $23.3 \pm 1.2(24)$ & $16.4 \pm 19.9(8)$ & $20.4 \pm 11.9(16)$ \\
\hline Baseline symptom severity $^{b, c}$ & $37.3 \pm 13.0(37.5)$ & $35.1 \pm 6.9(35)$ & $30.4 \pm 6.5(29.5)$ \\
\hline Age at first mania (yrs) ${ }^{d}$ & $23.8 \pm 11.6(19)$ & $27.1 \pm 10.2(27.5)$ & $25.6 \pm 7.1(23.5)$ \\
\hline Number previous manias ${ }^{b}$ & $13.0 \pm 17.0(13)$ & $3.0 \pm 2.7(2.5)$ & $3.6 \pm 1.7(3)$ \\
\hline Age at first depression (yrs) & $19.0 \pm 2.6(19)$ & $20.3 \pm 8.3(18.5)$ & $21.8 \pm 6.3(20)$ \\
\hline Number previous depressions ${ }^{b}$ & $14.0 \pm 15.6(14)$ & $3.6 \pm 2.2(4)$ & $5.9 \pm 6.0(3.5)$ \\
\hline Preliminary phase treatment $(\mathrm{I} / \mathrm{C})^{a, f}$ & $2 / 2$ & $4 / 4$ & $5 / 5$ \\
\hline Preventative phase treatment $(\mathrm{I} / \mathrm{C})^{a, f}$ & $0 / 4$ & $5 / 3$ & $6 / 4$ \\
\hline
\end{tabular}

All values are reported as mean $\pm \mathrm{SD}$ (median), or counts.

aData analyzed by chi-square.

${ }^{b}$ Data could not be normalized by log transformation and were analyzed by Kruskal-Wallis test.

'Manic (M), depressed (D), mixed (X), cycling (C).

${ }^{d}$ Data analyzed by ANOVA; if necessary, data were normalized by transformation as $\log (x)$ or $\log (x+1)$.

${ }^{e}$ Sum of Bech-Rafaelsen mania rating plus 25-item Hamilton depression rating.

fInterpersonal and Social Rhythm Therapy (I) or Standard Medication Clinic (C).

assignment in the preliminary or preventative phase of the study (Table 1). All of the dropouts had been assigned to standard medication clinic management rather than IPSRT for preventative phase treatment, but this difference from the other groups did not attain statistical significance.

Regarding the use of adjunctive medications during the preventative phase, as noted, the majority of patients were treated with lithium alone. Of two patients who received lithium plus tranylcypromine, one was a dropout and the other was a 1-year completer. One additional subject was treated with lithium plus thioridazine and was a 1-year completer.

The magnitude of transport inhibition by lithium is a function of the drug dose. Thus, it is important to recognize that the three outcome groups did not differ with respect to the mean daily dose or serum level of lithium during the 1-month stabilization period immediately preceding the measurement of $k_{\text {exch }}$. Specifically, the mean $\pm \mathrm{SD}$ lithium dose $(\mathrm{mg} /$ day) during this period was $1387.5 \pm 394$ for dropouts, $1107 \pm 398$ for recurrences, and $1324 \pm 377$ for 1-year completers (ANOVA, $F=0.97, p>.4$ ); the mean \pm SD serum lithium level (mmoles/L) during this period was $0.80 \pm 0.10$ for dropouts, $0.79 \pm 0.13$ for recurrences, and $0.83 \pm 0.09$ for 1-year completers (ANOVA, $F=0.29, p>0.75$ ). Thus, there were no significant differences found for either measure among the subject groups.

\section{Lithium Transport Findings}

Table 2 provides the values of $k_{\text {total }}$ and $k_{\text {passiver }}$ as well as $\mathrm{k}_{\mathrm{exch}}$, for subjects in the various outcome groups. Fig- ure 1 shows a plot of RBC lithium versus time for a representative subject during the 90-minute incubation procedure and demonstrates that RBC lithium efflux was linear under the conditions of these experiments.

As Figure 2 illustrates, the majority of completers manifested low values of $k_{\text {exch }}$, consistent with a high

Table 2. Rate Constant Data for Outcome Groups

\begin{tabular}{llll}
\hline Subject ID & $k_{\text {total }}$ & $k_{\text {passive }}$ & $k_{\text {exch }}$ \\
\hline Dropouts & & & \\
27214 & 0.376 & 0.027 & 0.349 \\
27224 & 0.149 & 0.004 & 0.145 \\
27226 & 0.220 & 0.033 & 0.187 \\
27231 & 0.519 & 0.044 & 0.475 \\
Recurrences & & & \\
27207 & 0.204 & 0.043 & 0.161 \\
27211 & 0.389 & 0.018 & 0.371 \\
27213 & 0.326 & 0.045 & 0.281 \\
27218 & 0.198 & 0.005 & 0.193 \\
27233 & 0.114 & 0.007 & 0.107 \\
27234 & 0.139 & 0.051 & 0.088 \\
27242 & 0.399 & 0.034 & 0.365 \\
27801 & 0.429 & 0.044 & 0.385 \\
One-year completers & & & \\
27208 & 0.123 & 0.031 & 0.092 \\
27212 & 0.087 & 0.009 & 0.078 \\
27215 & 0.327 & 0.025 & 0.302 \\
27216 & 0.101 & 0.030 & 0.071 \\
27217 & 0.156 & 0.053 & 0.103 \\
27219 & 0.109 & 0.022 & 0.087 \\
27221 & 0.114 & 0.044 & 0.070 \\
27223 & 0.274 & 0.039 & 0.235 \\
27230 & 0.265 & 0.041 & 0.224 \\
27232 & 0.159 & 0.064 & 0.095 \\
\hline & & &
\end{tabular}


degree of lithium transport inhibition. The values in this group tended to be homogeneous and were not normally distributed (Wilk-Shapiro test, $W=0.76, p<$ .005). The $\mathrm{k}_{\text {exch }}$ values for noncompleters (recurrences and dropouts) were scattered over a wider range. Median $\mathrm{k}_{\text {exch }}$ values were $0.09 \mathrm{~h}^{-1}$ for 1-year completers, $0.24 \mathrm{~h}^{-1}$ for patients with recurrences, and $0.27 \mathrm{~h}^{-1}$ for dropouts. Thus, median $k_{\text {exch }}$ was more than twofold higher in subjects who experienced recurrences or dropped out than in completers. There was a significant difference in $\mathrm{k}_{\text {exch }}$ for the three groups (Kruskal-Wallis test, $p<.03$ ). Post hoc testing indicated that $\mathrm{k}_{\text {exch }}$ was significantly higher in the group experiencing a recurrence of illness than in the 1-year completers $(p<.05)$.

The analysis of $k_{\text {exch }}$ data also was repeated after excluding the dropouts. When this was done, $k_{\text {exch }}$ was found to be significantly higher among recurrences than among 1-year completers (Mann-Whitney $\mathrm{U}$ test, $p<.03$ ). Moreover, when the recurrences and dropouts were combined into a single group of noncompleters $(n=12)$, a Mann-Whitney U test (corrected for ties) of the difference between noncompleters and 1-year completers was significant $(p<.01)$.

The values observed for $k_{\text {passive }}$ were similar in the three outcome groups. Mean $\pm \operatorname{SD} k_{\text {passive }}\left(\mathrm{h}^{-1}\right)$ values were $0.027 \pm 0.017$ for dropouts, $0.031 \pm 0.018$ for recurrences, and $0.036 \pm 0.016$ for 1 -year completers. There were no significant differences among the groups (ANOVA, $F=0.44, p>.65$ ).

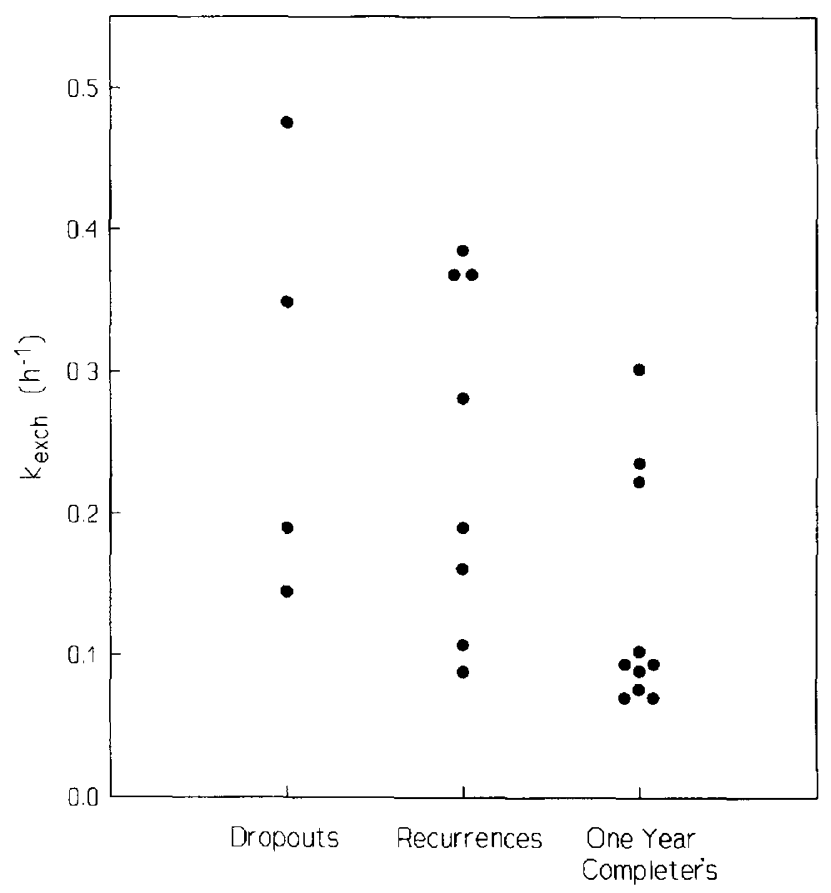

Figure 2. Measured values of the apparent rate constant for lithium efflux $\left(\mathrm{k}_{\mathrm{exch}}\right)$ in RBCs from patients categorized as dropouts, recurrences, or completers. Groupings were based on outcome for the first year of maintenance pharmacotherapy.

\section{Lithium Ratio Findings}

The in vivo RBC:plasma lithium ratio (LiR) in clinical blood specimens was measured monthly during the maintenance treatment trial. For noncompleters (recurrences and dropouts), the mean duration of treatment was 5.2 months. Therefore, we compared LiR data collected during the first half of the maintenance treatment year, as well as for the entire year. Figure 3 illustrates mean (+SD) LiR data for both the initial 6 months and the entire 12 months of treatment. LiR was significantly higher in completers than noncompleters, for both the initial 6-month data (mean $\pm \mathrm{SD} \mathrm{LiR}=0.62 \pm 0.12$ vs. $0.53 \pm 0.10$, respectively; $t=1.9, p<.04$ ) and the entire 12 -month data (mean $\pm \mathrm{SD} \mathrm{LiR}=0.61 \pm 0.11$ vs. $0.53 \pm$ 0.10 , respectively; $t=1.8, p<.05$ ). For the overall sample of 22 patients, there was a highly significant negative correlation between $\mathrm{k}_{\text {exch }}$ and LiR for both the initial 6-month data (Spearman rho $=-0.78, p<.0001$ ) and the entire 12 -month data (Spearman rho $=-0.75, p<.0001$ ).

As expected on the basis of the $k_{\text {exch }}$ data, mean LiR was lower in the patients who experienced a recurrence or dropped out, than among 1-year completers. This phenomenon is consistent with increased accumulation of intracellular lithium among 1-year completers as a

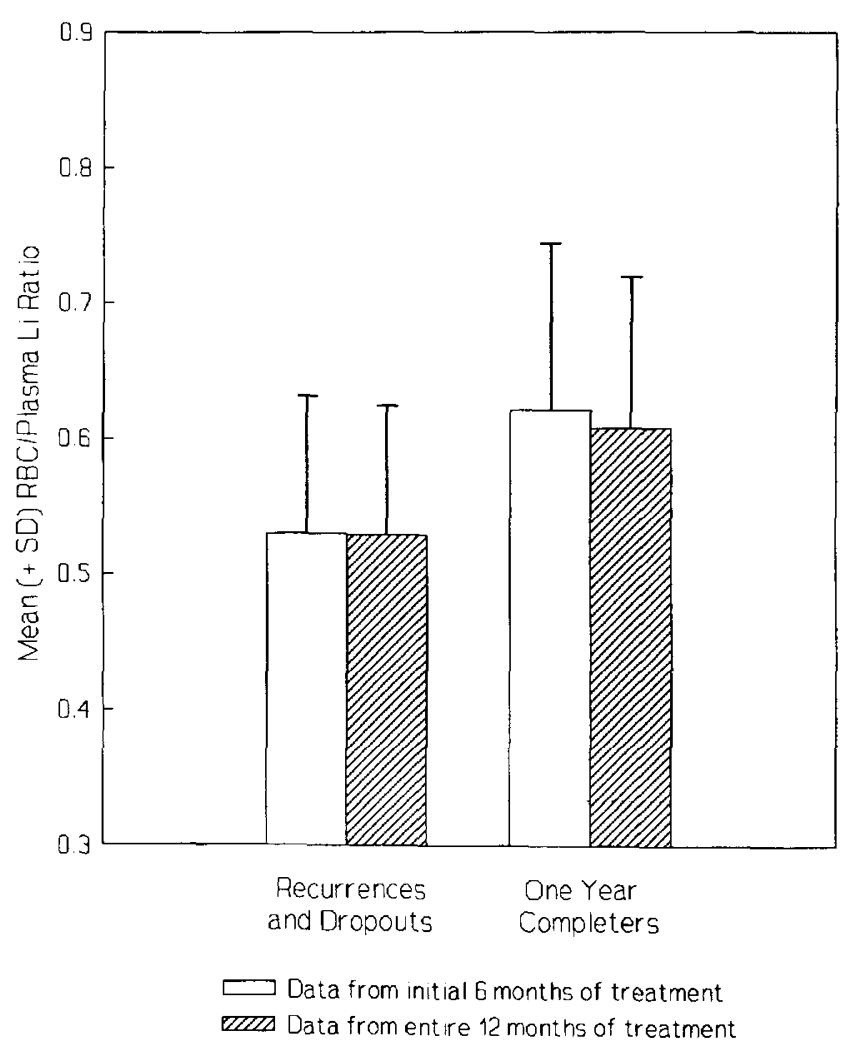

Figure 3. Mean (+ SD) RBC:plasma lithium ratio for both the initial 6 months (open bars) and entire 12 months (crosshatched bars) of the first year of maintenance pharmacotherapy. Data from noncompleters (recurrences and dropouts) are contrasted with the findings from one-year completers. 
result of inhibited lithium efflux via the $\mathrm{Na}^{+}-\mathrm{Li}^{+}$countertransport system. However, the LiR data appeared normally distributed, and showed no tendency to cluster at the extreme (as had been noted for $\mathrm{k}_{\text {exch }}$; see Figure 2).

There was no difference in LiR between the noncompleters who experienced recurrences and those who dropped out. For the initial 6-month data, mean \pm SD LiR was $0.54 \pm 0.07$ for recurrences vs. $0.52 \pm 0.16$ for dropouts $(t=0.21, p>.8)$. For the entire 12-month data, mean $\pm \mathrm{SD}$ LiR was $0.54 \pm 0.06$ for recurrences vs. $0.52 \pm$ 0.15 for dropouts $(t=0.30, p>.7)$.

\section{Plasma and Serum Lithium Findings}

Plasma lithium concentration is an important variable related to both clinical outcome and treatment compliance. This parameter was assessed monthly during the maintenance treatment trial. Target lithium levels were 0.8 to $1.0 \mathrm{mmoles} / \mathrm{L}$, although lower levels were permitted in cases of poor tolerance.

Plasma lithium concentrations were similar in noncompleters and completers, for both the initial 6-month data (mean $\pm \mathrm{SD}=0.77 \pm 0.10$ vs. $0.84 \pm 0.18$ mmoles $/ \mathrm{L}$, respectively; $t=1.2, p>.2$ ) and the entire 12-month data (mean $\pm \mathrm{SD}=0.78 \pm 0.10$ vs. $0.84 \pm 0.13$ mmoles $/ \mathrm{L}$, respectively; $t=1.2, p>.2$ ).

To obtain a separate index of compliance with lithium treatment, we also examined the serum level to daily dose (L:D) ratio, based on standard clinical serum lithium levels measured in the University of Pittsburgh Medical Center clinical toxicology laboratory. The L:D ratio is expected to be stable in a particular patient when lithium is being taken consistently. Therefore, we calculated the coefficient of variation $(\mathrm{CV})$ for the eight $\mathrm{L}: \mathrm{D}$ ratio values that most recently preceded the date of recurrence or dropout in noncompleters, or the end of the 1-year maintenance treatment interval in completers. These values originated from both the preliminary and preventative phases of the study. The CV of the L:D ratio did not differ significantly between noncompleters and completers (mean $\pm \mathrm{SD}=18.3 \pm 8.9$ vs. $17.6 \pm$ $7.1 \%$, respectively; $t=0.21, p>.8$ ), indicating a similar variability of the $\mathrm{L}: \mathrm{D}$ ratio in both outcome groups.

\section{DISCUSSION}

Several investigators have recently examined RBC lithium transport indices in relation to treatment outcome. Ghaemi et al. (1995) reported that among patients who were randomly assigned to lowered serum lithium levels following successful treatment at higher levels, RBC: plasma lithium ratios were significantly greater among patients who remained well than among those who experienced relapse. Indeed, the mean lithium ratios ob- served by these investigators for the total sample were comparable to those observed in the present study $(0.68$ for nonrelapse vs. 0.51 for relapse). Harvey and Kay (1991) reported that an index of variability of RBC lithium concentration based on five measurements over a 24-week period was significantly correlated with the relative relapse rate on lithium. They concluded that RBC lithium variability was an indicator of noncompliance and thereby was strongly related to relapse rate. No significant correlation was found between the relapse rate and mean serum lithium concentration or the mean RBC:serum lithium ratio. Other investigators suggested that changes in the RBC:plasma lithium ratio may be a result of noncompliance (Brunswick et al. 1978; Gengo et al. 1980).

In the present investigation, patients with low rates of lithium transport during clinical treatment with this agent (potentially reflecting a high degree of lithium transport inhibition) were more likely to have favorable outcome of maintenance pharmacotherapy. We cannot rule out the possibility that these low rates may have been present even prior to treatment and thus may reflect intrinsic membrane properties rather than a drug treatment effect. However, this latter possibility seems unlikely, as even the recurrence and dropout groups showed moderately low rates of transport, as evidenced by median $k_{\text {exch }}$ values of 0.24 and $0.27 \mathrm{~h}^{-1}$, respectively. By way of comparison, in a previous investigation of RBCs from 24 drug-free, bipolar subjects studied under similar in vitro conditions and loaded to initially contain $0.41 \pm 0.07$ mmoles lithium/L cells (mean $\pm S D$ ), the median $k_{\text {exch }}$ was substantially higher $\left(0.43 \mathrm{~h}^{-1}\right)$; likewise, in RBCs from 11 drug-free, normal control subjects loaded to initially contain $0.42 \pm 0.08$ mmoles lithium/L cells (mean $\pm S D$ ), the median $k_{\text {exch }}$ was 0.42 $\mathrm{h}^{-1}$ (A.G. Mallinger et al., unpublished data).

It may be that a high degree of lithium transport inhibition results from consistent medication compliance and that more sporadic medication-taking produces only moderate inhibition. In this case, measuring the $\mathrm{k}_{\text {exch }}$ could potentially provide an objective indicator of medication compliance. However, our analysis of L:D ratio data suggests an alternative interpretation, namely, that some patients may be resistant to the membrane actions of lithium on a biological level, despite reliable medication-taking behavior. The current study can only report on lithium transport inhibition as a predictor of maintenance treatment outcome and cannot distinguish between behavioral medication noncompliance and biological resistance to lithium.

Thus, measurement of $k_{\text {exch }}$ at an early point in treatment may provide a means for prospectively identifying bipolar patients who are at risk for failure of maintenance lithium therapy. Clearly there was overlap of the $\mathrm{k}_{\text {exch }}$ values observed in the subject groups (Figure 2). Nevertheless, it is noteworthy that $77 \%$ of patients 
with a $\mathrm{k}_{\text {exch }}$ of $0.11 \mathrm{~h}^{-1}$ or lower were successfully maintained on lithium for 1 year. In contrast, only $23 \%$ of patients with a $\mathrm{k}_{\text {exch }}$ greater than or equal to $0.12 \mathrm{~h}^{-1}$ had a successful treatment outcome. This represents a clinically meaningful level of predictive capability. Moreover, $\mathrm{LiR}$ may be useful as a secondary measure for monitoring lithium transport inhibition during ongoing lithium maintenance treatment. In a research clinic setting, both $\mathbf{k}_{\text {exch }}$ and LiR appear to be more robust in identifying potential treatment failures than the plasma lithium level.

Previous investigations have shown that lithium treatment alters the Michaelis-Menten kinetic curve for $\mathrm{Na}^{+}-\mathrm{Li}^{+}$countertransport in a way that suggests reduced affinity of intracellular transport sites for lithium (Ehrlich et al. 1981; Mallinger et al. 1990). This action could potentially have a generalized pharmacokinetic effect on the tissue distribution and levels of lithium. Thus, because a relatively greater concentration of intracellular lithium would be needed to maintain a given rate of efflux from cells, reduced affinity of transport sites for lithium could lead to intracellular accumulation of this ion, until the lithium concentration increased to a point at which a new equilibrium could be established between the cell and the extracellular environment. Increased intracellular lithium, in turn, could amplify the pharmacological actions of this drug on neurotransmitter, signal transduction, and other systems. In mechanistic terms, the better clinical outcome noted in patients with low $k_{\text {exch }}$ (which potentially results from reduced affinity of transport sites for lithium) could be related to greater intracellular lithium levels.

Magnetic resonance spectroscopy techniques have been utilized to measure brain lithium concentrations in bipolar patients during clinical treatment (Kato et al. 1994; Sachs et al. 1995). Such methodology would be well suited to examining the hypothesis that increased intracellular accumulation of lithium in the brain is related to better outcome of lithium pharmacotherapy.

Further research is needed to ascertain whether the primary determinant of $k_{\text {exch }}$ in particular patients during lithium treatment is behavioral medication compliance, biological responsiveness to membrane actions of lithium, or intrinsic pretreatment differences in membrane lithium transport. Perhaps ultimately, if it can be shown that insufficient transport inhibition results from medication noncompliance, $k_{\text {exch }}$ or some similar measure could be used prospectively to identify patients who need more intensive clinical and psychoeducational efforts aimed at improving treatment adherence, thereby averting treatment failure. On the other hand, if either biological resistance to the transport-inhibiting actions of lithium or intrinsic differences in lithium transport can be shown to be associated with unsatisfactory outcome of lithium treatment, $\mathrm{k}_{\text {exch }}$ might help to identify patients who require alternative maintenance treatments such as anticonvulsants.

\section{ACKNOWLEDGMENTS}

This work was supported by Grants MH29618 and MH30915 from the National Institute of Mental Health. It was completed while two of the authors (E.F. and D.J.K.) were Fellows at the Center for Advanced Study in the Behavioral Sciences, where they received support from the John D. and Catherine T. MacArthur Foundation.

\section{REFERENCES}

Amsterdam JD, Rybakowski J, Gottlieb J, Frazer A (1988): Kinetics of erythrocyte lithium-sodium countertransport in patients with affective illness before and during lithium therapy. J Affect Dis 14:75-81

Brunswick DJ, Frazer A, Mendels J, Ramsey TA (1978): Red blood cell $\mathrm{Li}+$ to plasma $\mathrm{Li}+$ ratios. Are they related to plasma Li+ concentrations? Neuropsychobiology 4:121127

Diamond JM, Meier K, Gosenfeld LF, Jope RS, Jenden DJ, Wright SM (1983): Recovery of erythrocyte $\mathrm{Li}+/ \mathrm{Na}+$ countertransport and choline transport from lithium therapy. J Psychiatric Res 17:385-393

Duhm J, Eisenried F, Becker B, Greil W (1976): Studies on the lithium transport across the red cell membrane. I. $\mathrm{Li}^{+}$ uphill transport by the $\mathrm{Na}^{+}$-dependent $\mathrm{Li}^{+}$countertransport system of human erythrocytes. Pflugers Arch 364: 147-155

Ehrlich BE, Diamond JM, Gosenfeld L (1981): Lithiuminduced changes in sodium-lithium countertransport. Biochem Pharmacol 30:2539-2543

Ehrlich BE, Clausen C, Gosenfeld LF, Diamond JM (1984): Lithium concentration in the muscle compartment of manic-depressive patients during lithium therapy. J Psychiatric Res 18:139-148

Endicott J, Spitzer RL (1978): A diagnostic interview. Arch Gen Psychiatr 35:837-844

Frank E, Kupfer DJ, Ehlers CL, Monk TH, Cornes C, Carter S, Frankel D (1994): Interpersonal and social rhythm therapy for bipolar disorder: Integrating interpersonal and behavioral approaches. Behav Ther 17:143-149

Gengo F, Frazer A, Ramsey TA, Mendels J (1980): The lithium ratio as a guide to patient compliance. Compr Psychiatr 21:276-280

Ghaemi SN, Sachs GS, Truman CJ, Gelenberg AJ, Rosenbaum JF (1995): RBC:plasma lithium ratio and susceptibility to early relapse following lithium reduction. Proceedings of the Annual Meeting on New Clinical Drug Evaluation Unit Program.

Haas M, Schooler J, Tosteson DC (1975): Coupling of lithium to sodium transport in human red cells. Nature 258:425426

Harrow M, Goldberg JF, Grossman LS, Meltzer HY (1990): Outcome in manic disorders: A naturalistic follow-up study. Arch Gen Psychiatr 47:665-671

Harvey NS, Kay R (1991): Compliance during lithium treatment, intra-erythrocyte lithium variability, and relapse. J Clin Psychopharmacol 11:362-367

Kato T, Takahashi S, Inubushi T (1994): Brain lithium con- 
centration measured with lithium-7 magnetic resonance spectroscopy: A review. Lithium 5:75-81

Mallinger AG, Poust RI, Mallinger J, Himmelhoch JM, Neil JF, Koo E, Hanin I (1985): A pharmacokinetic approach to the study of cell membrane lithium transport in vivo. J Clin Psychopharmacol 5:78-82

Mallinger AG, Himmelhoch JM, Thase ME, Dippold CS, Knopf S (1990): Reduced cell membrane affinity for lithium ion during maintenance treatment of bipolar affective disorder. Biol Psychiatr 27:795-798

Meltzer HL, Kassir S, Dunner DL, Fieve RR (1977): Repression of a lithium pump as a consequence of lithium ingestion by manic-depressive subjects. Psychopharmacology 54:113-118

Pandey GN, Sarkadi B, Haas M, Gunn RB, Davis JM, Tosteson DC (1978): Lithium transport pathways in human red blood cells. J Gen Physiol 72:233-247

Price LH, Heninger GR (1994): Lithium in the treatment of mood disorders. N Eng J Med 331:591-598

Prien RF, Gelenberg AJ (1989): Alternatives to lithium for preventive treatment of bipolar disorder. Am J Psychiatr 146:840-848

Rybakowski J, Frazer A, Mendels J (1978): Lithium efflux from erythrocytes incubated in vitro during lithium carbonate administration. Commun Psychopharmacol 2: 105-112

Rybakowski J, Lehmann W, Kanarkowski R (1988): Erythrocyte lithium-sodium countertransport and total body lithium pharmacokinetics in patients with affective illness. Hum Psychopharmacol 3:87-93

Sachs GS, Renshaw PF, Lafer B, Stoll AL, Guimaraes AR, Rosenbaum JF, Gonzalez RG (1995): Variability of brain lithium levels during maintenance treatment: A magnetic resonance spectroscopy study. Biol Psychiatr 38:422-428

Spitzer RL, Endicott J, Robins E (1978): Research diagnostic criteria: Rationale and reliability. Arch Gen Psychiatr 35:773-782

Weder AB (1986): Red-cell lithium-sodium countertransport and renal lithium clearance in hypertension. $N$ Eng J Med 314:198-201 